\title{
Guidelines for managing acute bacterial meningitis in adults
}

\author{
Speed in diagnosis and treatment is essential
}

Nearly 1 in 4 adults with acute bacterial meningitis die, and many survivors sustain neurologic deficits. ${ }^{1,2}$ The outcome has not changed since the early 1960s despite the introduction of potent antibiotics and specialized intensive care units. ${ }^{3}$ Can anything further be done to optimize treatment and improve outcome?

The prognosis is worse with a delay in management. ${ }^{4}$ Consequently, the outcome depends on whether the attending physician suspects acute bacterial meningitis and whether the health care system is set up to make a rapid, accurate diagnosis and initiate fast and effective treatment.

In this respect, standardized guidelines such as those recently issued by the working party of the British Infection Society are invaluable. ${ }^{5}$ These guidelines make recommendations for the management of adults with suspected or diagnosed acute bacterial meningitis or meningococcal disease and for the prevention of secondary cases by vaccination and prophylactic antibiotic treatment. The guidelines may provide a template for treating acute bacterial meningitis for physicians in most countries. However, countries that now vaccinate against Haemophilus influenzae type $\mathrm{b}$ or meningococci serogroup $\mathrm{C}$ may see $\mathrm{a}$ change in the epidemiologic characteristics of bacterial meningitis.

There is little evidence on the best way to manage patients as soon as they present with acute bacterial meningitis. The new report advises family physicians to give benzylpenicillin (penicillin $G$ ) to any patients who may have acute bacterial meningitis before they are admitted to the hospital. With elderly patients, however, more caution may be needed. First, the outcome from acute bacterial meningitis has not been shown to be improved by the preadmission use of antibiotics; the crucial factor is probably whether the attending physician suspects acute bacterial meningitis at all and therefore arranges immediate admission to a hospital. Second, preadmission antibiotic use may make it harder to get a definitive microbial diagnosis.

For a young patient with suspected meningococcal disease, the immediate use of antibiotics, followed by rapid admission to a hospital, may be the best course of action. In patients with suspected bacterial meningitis of other causes, arranging rapid transfer to a hospital, followed by speedy microbiologic testing and antibiotic treatment, may be more prudent. After admission to the hospital, the widely accepted empiric treatment is the administration of a third-generation cephalosporin, such as cefotaxime sodium or ceftriaxone sodium, with ampicillin if listerial meningitis cannot be ruled out. In patients with obvious meningococcal disease, penicillin is the drug of choice.

The reduced susceptibility of pneumococci to penicillin is an increasing problem in large parts of the world; this may often be overcome by increasing the amount and frequency of doses, but rifampicin (rifampin) may be useful for pneumococci that are truly penicillin-resistant. ${ }^{6}$ Selecting the appropriate therapy for patients with acute bacterial meningitis who are hypersensitive to $\beta$ lactams is difficult. Chloramphenicol is not ideal because of its low clinical efficacy and potential side effects; meropenem or broad-spectrum quinolones may be considered, although there is little evidence that they work.

Supportive treatment has been hotly debated. Corticosteroids reduce neurologic deficits in children with $H$ influenzae meningitis, whereas their beneficial effect in adults remains to be proved. ${ }^{7}$ It is hoped that the results of the multicenter European trial on dexamethasone use in acute bacterial meningitis, scheduled to end in a year, will provide conclusive evidence. The use of glycerol or mannitol may reduce intracranial pressure when there is intracranial hypertension. ${ }^{8}$ The need for full fluid replacement and maintenance is rightfully emphasized in the guidelines. Fluid restriction does not lessen brain edema or improve outcome in patients with acute bacterial meningitis. ${ }^{9,10}$ Furthermore, cerebral perfusion depends on the mean arterial blood pressure in these patients and is adversely affected by hypovolemia. ${ }^{11}$ Also, these patients are at risk of sepsis with hypotension. In general, many patients with acute bacterial meningitis need intensive care to monitor and treat both cerebral and extracerebral complications.

The guidelines are the laudable result of a major effort from the working party and should be disseminated to all physicians. An increased awareness of acute bacterial meningitis with emphasis on speedy diagnosis and treatment will serve patients well.

References

1 Pfister HW, Feiden W, Einhäupl KM. Spectrum of complications during bacterial meningitis in adults: results of a prospective clinical study. Arch Neurol 1993;50:575-581.
Kirsten Møller

Research Fellow Peter Skinhøj

Professor

Department of Infectious Diseases 5132

University Hospital Rigshospitalet Copenhagen, Denmark

Correspondence to: Dr Møller

kirsten.moller@ dadlnet.dk

Competing interests: None declared

This editorial was previously published in BMJ 2000;320:1290 
2 Bohr V, Hansen B, Kjersem H, et al. Sequelae from bacterial meningitis and their relation to the clinical condition during acute illness, based on 667 questionnaire returns: part II of a three part series. J Infect 1983;7:102-110.

3 Durand ML, Calderwood SB, Weber DJ, et al. Acute bacterial meningitis in adults: a review of 493 episodes. $N$ Engl J Med 1993;328:21-28.

4 Aronin SI, Peduzzi P, Quagliarello VJ. Community-acquired bacterial meningitis: risk stratification for adverse clinical outcome and effect of antibiotic timing. Ann Intern Med 1998;129:862-869.

5 Begg N, Cartwright KAV, Cohen J, et al. Consensus statement on diagnosis, investigation, treatment and prevention of acute bacteria meningitis in immunocompetent adults: British Infection Society Working Party. I Infect 1999;39:1-15.

6 Reacher MH, Shah A, Livermore DM, et al. Bacteraemia and antibiotic resistance of its pathogens reported in England and Wales between 1990 and 1998: trend analysis. BMJ 2000;320:213-216.
7 Lebel MH, Freij BJ, Syrogiannopoulos GA, et al. Dexamethasone therapy for bacterial meningitis: results of two double-blind, placebo-controlled trials. $N$ Engl J Med 1988;319:964-971.

8 Kilpi T, Peltola H, Jauhiainen T, Kallio MJ. Oral glycerol and intravenous dexamethasone in preventing neurologic and audiologic sequelae of childhood bacterial meningitis: the Finnish Study Group. Pediatr Infect Dis J 1995;14:270-278.

9 Täuber MG, Sande E, Fournier MA, Tureen JH, Sande MA. Fluid administration, brain edema, and cerebrospinal fluid lactate and glucose concentrations in experimental Escherichia coli meningitis. J Infect Dis 1993; 168:473-476.

10 Singhi SC, Singhi PD, Srinivas B, et al. Fluid restriction does not improve the outcome of acute meningitis. Pediatr Infect Dis J 1995; $14: 495-503$

11 Møller K, Larsen FS, Qvist J, et al. Dependency of cerebral blood flow on mean arterial pressure in patients with acute bacterial meningitis. Crit Care Med 2000;28:1027-1032.

\section{A book that made me think}

Bioethics: An Anthology, Helga Kuhse, Peter Singer, eds. Blackwell Publishers, \$39.95, pp 600, ISBN 0631 203117

Peter Singer was a keynote speaker at the last annual meeting of the American Society of Bioethics and Humanities in Philadelphia. For various reasons, I had chosen this moment in the program to duck out of the conference. I was completely unprepared for what greeted me as I left the hotel-protesters, many confined to wheelchairs, chanting "Less debate, more hate." This, I discovered, was the disability activist group Not Dead Yet, which is incensed about Singer's stance that some people with disabilities are not "persons" and may be killed or allowed to die with impunity. It is rare for philosophers to incite the ire of the community at large. Socrates and Bertrand Russell did, and now it seems Peter Singer has joined the ranks of infamy.

I am disappointed by Kuhse and Singer's edited collection of philosophical papers on bioethics. The selection is deeply conservative, and it eschews literature at the margins of bioethics. This is a shame because contemplation of narrative ethics, anthropology, families, and communities is where the action has been in bioethics during the past decade. My attention was naturally drawn to the four essays by Singer himself in the volume. Here, I was not disappointed but offended. Singer variously concluded that experimenting on a human embryo is preferable to doing so on a mouse; that chimpanzees are properly called "people," but humans with profound cognitive impairments are not; and that the heart of a handicapped newborn human might be legitimately excised to save a baboon in need of a new heart. Some have argued that Singer is not responsible for these absurd conclusions since he is merely working through the logical outcomes of a particular moral theory, utilitarianism. Whatever faults we may find with the outcome are properly attributed to the theory and not the philosopher. I disagree: Singer is culpable for these views because doing ethics responsibly involves more than logical reasoning alone. Moral intuition acts as an important check on ethical reasoning, telling us that at times it is the theory, not our actions, that must be changed. More than once Singer notes, "At first this sounds crazy," and more than once he fails for not paying attention to his own intuition.

My reaction to Singer's work is akin to discovering that a friend has served me her pet for dinner. As my initial reaction of disgust fades, I would wonder whether the animal was really a pet, and, if it was, whether my friend actually understands what it means to have a pet. Having a pet implies a set of rules describing the proper relationship between owner and pet and not eating one's pet is high on the list. The terms "person" and "animal" come with their own sets of rules, embedded deep within our society, defining relationships among human beings and between people and animals. Singer, in suggesting that these terms or the rules associated with them may be interchangeable, demonstrates that he fails to understand the concepts of "person" and "animal" at all.

Charles Weijer, bioethicist

Dalhousie University, Halifax, Canada

This review first appeared in the $B M J$ 2000;320:1215 